October 2015

\title{
The Crisis at Home following the Crisis Abroad: Health Care Deficiencies for US Veterans of the Iraq and Afghanistan Wars
}

Nema Milaninia

Follow this and additional works at: https://via.library.depaul.edu/jhcl

\section{Recommended Citation}

Nema Milaninia, The Crisis at Home following the Crisis Abroad: Health Care Deficiencies for US Veterans of the Iraq and Afghanistan Wars, 11 DePaul J. Health Care L. 327 (2008)

Available at: https://via.library.depaul.edu/jhcl/vol11/iss3/4

This Article is brought to you for free and open access by the College of Law at Digital Commons@DePaul. It has been accepted for inclusion in DePaul Journal of Health Care Law by an authorized editor of Digital Commons@DePaul. For more information, please contact digitalservices@depaul.edu. 


\title{
THE CRISIS AT HOME FOLLOWING THE CRISIS ABROAD: HEALTH CARE DEFICIENCIES FOR US VETERANS OF THE IRAQ AND AFGHANISTAN WARS
}

\author{
Nema Milaninia* \\ INTRODUCTION
}

A side of war often reviewed by political analysts and in publishable studies is conflict's effects on social resources. While these studies focus on budgeting struggles and military spending, the health concerns and right of military veterans upon their return to the United States has been vastly overlooked and understudied. The current military conflicts in Afghanistan and Iraq highlight these issues. As a result of both wars, thousands of Americans have been placed into combat zones where they face threats to both their physical and mental well-being. Consequently, more than 28,000 U.S. military service members, including members of the National Guard and Reserve, have been injured in both Operation Enduring Freedom ("OEF") and Operation Iraqi Freedom ("OIF")."

Given that the inherent nature of war is the creation of death and impairment, it is precisely through years of military conflict that the United States has developed what has previously been considered a hallmark in veteran care. Once veterans return from combat zones the path to self-reconciliation is laid out before them. Upon return they are automatically entitled to benefits and health care at any VA facility. ${ }^{2}$

\footnotetext{
* Nema Milaninia is an attorney at Wilson Sonsini Goodrich \& Rosati PC where he specializes in white collar criminal defense and investigation. He is also currently the executive director of the International Studies Journal, a publication on human rights, democracy and international relations based out of Tehran, Iran. Mr. Milaninia received his B.A. in Political Science from the University of California, San Diego and his J.D. from the University of California, Hastings College of the Law. Mr. Milaninia would like to thank Mahnoosh Nik-Ahd and Kari Kammel for their tireless efforts in putting this article together.

${ }^{1}$ Hannah Fischer, United States Congressional Research Service. United States Military Casualty Statistics: Operation IRAQI FreEdom and OPERATION ENDURING FREEDOM (Aug. 17, 2007), available at http://www.fas.org/ sgp/crs/natsec/RS22452.pdf.

${ }^{2}$ Id. (Automatic entitlement without enrollment only applies to veterans who have been rated as $50 \%$ or more service-connected; where less than one year has passed since they were discharged from military service for a disability that the military determined incurred or aggravated in the line of duty, or where the veteran is seeking care for a service-connected disability only).
} 
Those with serious physical and psychological injuries are initially treated at the Department of Defense's (DoD) major military treatment facilities. The Department of Veterans Affairs (VA) has made provision of services to these service members a high priority. ${ }^{3}$

However, growing health care needs by soldiers returning from Iraq combined with the number of veterans already receiving treatment from past conflicts and service has overwhelmed VA hospitals with patients. ${ }^{4}$ Last year, the VA system handled a record number of claims, approximately 838,000 , prompting the VA to hire 3,700 new "mental health physicians" bringing the total to 17,000 physicians specializing in health care. ${ }^{5}$ Despite these increases, the VA system is incapable of handling the current number of patients in need of health care services, specifically mental care assistance. ${ }^{6}$ The incidents of care are fundamentally based on the type of warfare military units engage in Afghanistan and Iraq. The unconventional nature of battles has resulted in a higher degree of mental stress despite the decrease in physical injuries and casualties. ${ }^{7}$ According to a recent report release by the RAND Corporation, over 300,000 , or approximately $20 \%$ of deployed trips, suffer from depression or post-traumatic stress from serving in Iraq and Afghanistan. ${ }^{8}$ According to recent correspondence by top VA officials, an average of 18 war veterans commit suicide a day (or 6.552 per year), 5 per day while under the supervision and care of the VA. ${ }^{9}$ Studies have shown that exposure to combat is significantly greater amongst those deployed to Iraq than those

${ }^{3}$ Vocational Rehabilitation, More VA and DoD Collaboration NeEded to EXPEDITE SER VICES FOR SERIOUSLY INJURED SERVICEMEMBERS, GAO Report 06-167 (Jan. 2005) available at $\mathrm{http} / / \mathrm{www}$.gao.gov/highlights/d05167high.pdf.

${ }^{4}$ See Anne Hull \& Dana Priest, It is Just Not Walter Reed, WASH. Post, March 5, 2007, available at http://www.washingtonpost.com/wp-dyn/content/article/2007/ 03/04/AR2007030401394.html.

${ }^{5}$ Paul Elias, VA Urges Dismissal of Health Care Lawsuit, THE MERCURY News, Apr. 21, 2008 available at http://www.mercurynews.com/news/ci_9004226 (last visited Apr. 23 2008).

6 Maggie Shiels, U.S. Veterans Sue Over 'Poor Care,' BBC News OnLINE, http://news.bbc.co.uk/2/hi/americas/7357909.stm (last visited Apr. 25, 2008).

${ }^{7}$ See generally BRUCE MiChaEL BONGAR, PsYCHOLOGY OF TERRORISM 165 (2006).

8 See generally INVISIBLE WOUNDS OF WAR: PSYCHOLOGICAL AND COGNITIVE INJURIES, THEIR CONSEQUENCES, AND SERVICES TO ASSIST RECOVERY (Terri Tanilian \& Lisa H. Jaycox, eds., 2008), available at http://rand.org/pubs/monographs/ 2008/RAND_MG720.pdf.

${ }^{9}$ Patricia Cohen, Talking Veterans Down from Despair, N.Y. TIMES ONLINE, Apr. 22, 2008, http://www.nytimes.com/2008/04/22/us/22suicide.html?_r=1\&oref=slogin (last visited Apr. 25, 2008). 
deployed to Afghanistan. ${ }^{10}$ As a result, the percentage of those who suffer from psychological problems, including Post Traumatic Stress Disorder (PTSD), is significantly higher amongst those deployed in Iraq. ${ }^{11}$ Studies indicate that among soldiers returning from Iraq, approximately $19.1 \%$ screened positive for mental health concerns as compared to $11.3 \%$ returning from Afghanistan, and $8.5 \%$ returning from other deployments. ${ }^{12}$ Despite the high number of soldiers with mental health concerns, only $20-40 \%$ of veterans showing evidence of psychological harm actually sought mental health care. ${ }^{13}$

Rising concern for the mental health of veterans is justified given the onslaught of a number of mental health problems suffered by recent veterans and the effects those problems have on the veterans themselves. Common mental illnesses felt by veterans are major depression, generalized anxiety and PTSD. ${ }^{14}$ These shifts include reduced proficiency in sustained attention and memory, heightened negative state affect reflecting increased feelings of confusion and tension, and an advantage in reaction time. ${ }^{15}$ Studies suggest that mental status changes related to Iraq War participation extend beyond psychiatric concerns to circumscribed adverse neuropsychological consequences, an outcome domain with high relevance to occupational

${ }^{10}$ The prevalence of reporting a mental health problem was $19.1 \%$ among service members returning from Iraq compared with $11.3 \%$ after returning from Afghanistan and $8.5 \%$ after returning from other locations. Charles W. Hoge et al., Mental Health Problems, Use of Mental Health Services, and Attrition From Military Service After Returning From Deployment to Iraq or Afghanistan, 295 J. AM. MED. Ass'N 1023 (2006) (the prevalence of reporting a mental health problem was $19.1 \%$ among service members returning from Iraq compared with $11.3 \%$ after returning from Afghanistan and $8.5 \%$ after returning from other locations); see also Charles W. Hoge, et al., Mental Disorders Among U.S. Military Personnel in the 1990's: Association with High levels of Health Care Utilization and Early Military Attrition, 159 AM. J. PSYCHIATRY 1576, 1576-1583 (2002).

${ }^{11}$ Matthew J. Friedman et al., Post-traumatic Stress Disorder in the Military Veteran. 17 Psychiatric. Clinic North Am. 265 (1994).

${ }^{12}$ Charles W. Hoge et al., Mental Health Problems After Deployment to Iraq or Afghanistan, 295 J. AM. MED. Ass'N 519 (2006).

${ }^{13}$ Id., See also Jennifer J. Vasterling et al., Neuropsychological Outcomes of Iraq War Army Personnel, 296 J. AM. MED. Ass'N 519 (2006).

${ }^{14}$ Charles W. Hoge et al., Combat Duty in Iraq and Afghanistan, Mental Health Problems, and Barriers to Care. 351 N. ENGL. J. MED. 13, 22 (2004) [hereinafter Hoge, Combat Duty in Iraq and Afghanistan].

${ }^{15} \mathrm{Id}$. 
and psychosocial functioning and highly sensitive to brain dysfunction. $^{16}$

Particularly, there are unique factors in the military that contribute to resistance by soldiers from seeking help, including concerns about how one will be perceived by their peers and by the leadership. ${ }^{17}$ Concern about stigma is disproportionately greatest among those most in need of help from mental health services. ${ }^{18}$ In fact, veterans who test positively for mental disorder are twice as likely as those who test negative for mental disorder to show concern about being stigmatized and about other barriers to mental health care. ${ }^{19}$

Efforts to address the problem of stigma and other barriers to seeking mental health care in the military should take into consideration outreach, education, and changes in the models of health care delivery, such as increases in the allocation of mental health services in primary care clinics and in the provision of confidential counseling by means of employee-assistance programs. ${ }^{20}$ According to VA/DOD clinical practice guideline for the management of major depressive disorder in adults, screening for major depression is becoming routine in military primary care settings. ${ }^{21}$ However, studies clearly suggest that the standard practices should be expanded to include screening for PTSD and in fact many of these considerations are being addressed in new military programs. $^{22}$ Reducing the perception of stigma and the barriers to care among military personnel

\footnotetext{
16 Jennifer J. Vasterling et al., Neuropsychological Outcomes of Iraq War Army Personnel, 296 J. AM. MED. Ass'N 519 (2006).

${ }^{17}$ Hoge, Combat Duty in Iraq and Afghanistan, supra note 14, at 22.

${ }^{18}$ Id.

${ }^{19}$ Ronald C. Kessler et al., The Epidemiology of Major Depressive Disorder: Results
} From the National Comorbidity Survey Replication (NCS-R). 289 J. AM. MED. AsS'N 3095, 3195 (2003); see also D.A. Regier et al., The De Facto US Mental and Addictive Disorders Service System: Epidemiologic Catchment Area Prospective 1year Prevalence Rates of Disorders and Services. 50 ARCH. GEN. PSYCHIATRY 85, 94 (1993); Ronald C. Kessler et al., Lifetime and 12-month prevalence of DSM-III-R psychiatric disorders in the United States: results from the National Comorbidity Survey, 51 ArCH. GEN. PsychIATRy 8, 8-19 (1994).

${ }^{20}$ Charles W. Hoge, Jennifer L. Auchterlonie, \& Charles S. Milliken, Mental Health Problems, Use of Mental Health Services, and Attrition After Returning After Deployment to Iraq or Afghanistan, 295 J. AM. MED. Ass'N 1023, 1030 (2006).

21 VHA/DOD Clinical Practice GuIdeline for the Management of Major DEPRESSIVE DISORDER IN ADULTS, at $\mathrm{i}$, available at http://www.oqp.med.va.gov/ cpg/MDD/D/MDD_CPG_v21.PDF.

22 Deployment Health Clinical Center. Deployment Cycle Support and CliniCIANS - PRACTICE GUIDELINES, available at http://www.pdhealth.mil/guide lines/downloads/download/2/guideline_ver1.2.pdf. 
is a priority for research and a priority for the policymakers, clinicians, and leaders who are involved in providing care to those who have served in the armed forces.

Nevertheless, there is still a high rate of mental health service utilization among veterans from both OIF and OEF. Approximately one third of OIF veterans accessed mental health services in their first year after deployment and within that population, $12 \%$ per year received a diagnosis of a mental health problem and an additional $23 \%$ per year were seen in mental health clinics but did not receive a diagnosis. $^{23}$ It is not clear why there was such high use of mental health services without a mental illness diagnosis. ${ }^{24}$ Since the year 2000 , there have been significant increases in the mental health care use of the United States military, evidencing further burden on the health care system altogether. ${ }^{25}$ These findings highlight the challenges in assuring that staffing levels of mental health services are sufficient to meet the needs of returning veterans.

That being said, studies have shown that $56 \%$ of OIF veterans and other deployments referred to mental health care received a mental health evaluation either in the primary care or specialty mental health care setting. ${ }^{26}$ This is higher than what has been evidenced in civilian studies. In fact, it is likely that the rate within the military population is higher because in civilian settings mental heath services can often be provided in non-medical settings, such in family structures, religious institutions, or other traditional social service settings. ${ }^{27}$ The high percentage of veterans receiving mental health care, however, contributes to the current burdens being faced by VA hospitals and clinics.

According to a 2002-03 Government Accountability Office study, nearly one third of VA medical centers fail to offer home health services (as they are required to do) and some improperly deny them to eligible, but non-service-connected, veterans; in response, the VA promised in 2003 to begin making home health care more widely and equally available. $^{28}$ Of the 139 facilities of the VA, 126 do not cover

${ }^{23}$ Hoge, supra note 14 , at 1030.

${ }^{24}$ Id.

${ }^{25} \mathrm{Id}$. at 1031 .

${ }^{26}$ Id. See also M. Grunebaum, et al., Predictors of Missed Appointments for Psychiatric Consultations in a Primary Care Clinic. 47 PSYCHIATRIC SERV. 848-852 (1996).

${ }^{27}$ Hoge, supra note 14 , at 1031.

28 Gen. ACCOUNTING OfFICE, RePt. No. GAO-03-487, VA LONG TERM Care: SERVICE GAPS AND FACILITY RESTRICTIONS LIMITED VETERANS' ACCESS TO 
all six of the non-institutional services required by law (adult day health care, geriatric evaluation, respite care, home-based primary care, homemaker/home health aide, and skilled home health care). ${ }^{29}$ Moreover, Veterans Aid is generally limited to only those geographic areas in which they serve and do not tend to offer services outside those areas. $^{30}$

As recently reported by the Washington Post, the result of these burdens have turned the Walter Reed hospital, (perceived as the hallmark of the VA medical system) into "a holding ground for physically and psychologically damaged outpatients." As detailed by the Post:

Almost 700 of them-the majority soldiers, with some Marines-have been released from hospital beds but still need treatment or are awaiting bureaucratic decisions before being discharged or returned to active duty. They suffer from brain injuries, severed arms and legs, organ and back damage, and various degrees of post-traumatic stress. Their legions have grown so exponentially-they outnumber hospital patients at Walter Reed 17 to 1 - that they take up every available bed on post and spill into dozens of nearby hotels and apartments leased by the Army. The average stay is 10 months, but some have been stuck there for as long as two years. ${ }^{31}$

In addition to adding extensive burden on the health care system, studies show that the mental health concerns are intimately connected with attrition in military service. ${ }^{32}$ Specifically, studies conducted prior to OIF and OEF have documented that "mental disorders are the leading medical correlate with attrition from military service.",33 There is also documented data confirming that mental health problems associated with military service have significant occupational effects. ${ }^{34}$ Subsequently, the connection between high rates of mental health

NONINSTITUTIONAL CARE 3-4 (2003), available at http://www.gao.gov/cgibin/getrpt?GAO-03-487.

${ }^{29} I d$ at 4.

${ }^{30} \mathrm{Id}$.

${ }^{31}$ Dana Priest \& Anne Hull, Soldiers Face Neglect, Frustration at Army's Top Medical Facility, WASH. POST, Feb. 18, 2007, at A01.

${ }^{32}$ Hoge, supra note 14 , at 1031.

${ }^{33}$ Id. See also New FreEdom Commission on Mental Health, Achieving the PRomise: TRANSForming MENTAL HEALTH CARE IN AMERICA (2003).

${ }^{34}$ Hoge, supra note 14 , at 1031. 
concerns and the high use of VA services has important implications for projecting the needs for mental health services in the VA health care system. $^{35}$

However, despite efforts by policymakers and physicians to address the medical needs of veterans, the current legal model for addressing veteran claims is more likely to deteriorate the overall quality of care veterans receive. This paper evaluates the struggles presented by rising veteran demands for medical care and compensation.

\section{VETERAN CLAIMS FOR HEALTH AND COMPENSATION BEFORE JUDICIAL BODIES}

A significant portion of military forces returning from conflicts in Iraq and Afghanistan are in need of health care. As studies show, approximately one third of OIF veterans accessed mental health services in their first year after deployment. ${ }^{36}$ Out of those individuals, approximately $12 \%$ received a diagnosis of a mental health problem per year. ${ }^{37}$ Additionally, $23 \%$ per year were not diagnosed after being seen in mental health clinics. ${ }^{38}$ Studies show that these rates parallel combat experiences reported by soldiers returning from other wars; thus, emphasizing that mental health services is likely to vary as a function

${ }^{35}$ See generally Charles W. Hoge et al., Mental Disorders Among U.S. Military Personnel in the 1990's: Association With High levels of Health Care Utilization and Early Military Attrition, 159 AM. J. PSYCHIATRY 1576 (2002) (discussing the burden of mental disorders on the utilization of health care.); Abigail L. Garvey-Wilson et al., Scientific and Clinical Report Session 18-Epidemiology No. 53 - Diagnosis in Behavioral Health Clinics: Impact on Perceived Burden of Mental Health, 2003 AM. PSYCHIATRY ASS'N SYllabUS AND PROC. ANN. MEETING, available at http://archive.psych.org/edu/other_res/lib_archives/archives/meetings/AMS/2003saps .cfm (last visited Apr. 1, 2008); Charles W. Hoge et al., The Occupational Burden of Mental Disorders in the U.S. Military: Psychiatric Hospitalization, Involuntary Separations, and Disability, 162 AM. J. PSYCHIATRY 585 (2005) (discussing the relationship between the high utilization of health care services by U.S. military and occupational morbidity).

${ }^{36}$ Charles W. Hoge et al., Mental Health Problems, Use of Mental Health Services, and Attrition From Military Service After Returning From Deployment to Iraq or Afghanistan, 295 J. AM. MED. Ass'N 1023 (2006).

${ }^{37}$ Id.

${ }^{38}$ Id. See also Roberto J. Rona, Screening for Psychological Illness in Military Personnel 293 J. AM. MED. Ass'N 1257 (2005) (discussing how the presentation of psychological symptoms by veterans does not always amount to a clinical diagnosis of a given disorder). 
of combat exposure. ${ }^{39}$ Moreover, OIF veterans show a higher rate of use of mental health services in their first year after returning from deployment than veterans returning from other locations. ${ }^{40}$ This is a variant of conclusive evidence linking the exposure to combat experience and the need for mental health attention. Consequently, OIF veterans, who have faced heightened levels of combat exposure than combatants in Afghanistan, have created the greatest demands for medical care.

Among soldiers returning from Iraq, the reported rates of combat experiences and contact with the enemy are much higher than those reported by soldiers returning from Afghanistan or other combat zones. ${ }^{41}$ According to one study, only " $31 \%$ of soldiers deployed to Afghanistan reported having engaged in a firefight, as compared with 71 to 86 percent of soldiers and Marines who had been deployed to Iraq." Among those who had been in a firefight, the average solider in Afghanistan was involved in two firefights, as compared with five among Marines deployed to Iraq. ${ }^{42}$

Altogether the statistics show increasing need by the VA to provide for veterans returning home and that the characteristics of the Iraq war will create unprecedented demands on the VA. Yet despite the increasing need, general care provisions and legal limitations have, in large part, prevented satisfactory health conditions.

\section{A. General Care Provisions and Limitations}

The VA provides general benefits in compensation, pensions, health care, vocational rehabilitation and employment, education and training, home loans, life insurance, care for dependents and survivors, and in burials. ${ }^{43}$ Care available through the VA includes inpatient

${ }^{39}$ Hoge, Combat Duty in Iraq and Afghanistan, supra note 14, at 16-18.

${ }^{40} I d$.

${ }^{41} I d$. at $16-18$.

${ }^{42} I d$. at 16.

${ }^{43}$ By law, veterans' access to VA medical care is ranked by statutorily-defined "Priorities" (1 through 8). Patients are served only subject to the law's prioritization and care access, as a matter of basic reality, is constrained by the (limited) funds appropriated by Congress. Priority 5, 7 and 8 patients have many others who have priority before them- "service connected" disabled veterans, former prisoners of war, Medal of Honor winners, the "catastrophically disabled," recent returnees from combat zones and so on. This means that long waits for care, or specialty referrals, or lack of wide provider choices-and other medical "amenity" standards that would ordinarily be applicable within a civilian entitlement medical care program context- 
hospital stays, outpatient hospital services, clinic and physician services, surgery, complete laboratory and radiological services and outpatient prescription drugs. ${ }^{44}$ Yet much of the services, particularly pension and health care, depend upon the injury suffered by the veteran to be a form of harm acceptable under federal law for both recognition and compensation. ${ }^{45}$ For example, the VA provides combat veterans free medical care for any illness possibly associated with service during a period of hostility for two years from the veteran's release from active duty. ${ }^{46}$

However, despite the expansiveness of benefits offered to veterans, Congress specifically limits entitlement for service-connected disease or injury to cases where such incidents have resulted in a disability. ${ }^{47}$ In other words, the law limits entitlement for servicerelated diseases and injuries to cases where the underlying in-service incident has resulted in a current disability. ${ }^{48}$ As a result, many of the benefits that the VA is required to provide may be denied if the veteran does not sufficiently demonstrate that the disability is connected with military service.

\section{B. The Problems with "Service Connected" Care}

The requirement that the injury be "service connected" is often the basis of legal dispute by veterans in need of expansive medical coverage or pension plans, particularly when the degree of the disability has a significant economic impact. ${ }^{49}$ Veterans with service connected disabilities above $50 \%,{ }^{50}$ former prisoners of war, and any

simply do not have traction in the VA system. VA care is prioritized, space-available care and not an entitlement. Moreover, even valid legal claims against the VA for substandard or negligent care are seriously limited or prohibited by the legal doctrine of sovereign immunity. These realities mean that appeal rights-while they do nominally apply to medical care as well as other VA benefits-do not always offer timely or adequate redress.

${ }^{44} 38$ U.S.C. $\S 1701$ (2000).

${ }^{45} 38$ U.S.C. $\S \S 1110,1131(2000)$.

${ }^{46} I d$.

${ }^{47}$ Id.; see also Brammer v. Derwinski, 3 Vet. App. 223 (1992).

${ }^{48}$ Degmetich v. Brown, 104 F.3d 1328 (Fed. Cir. 1997); Rabideau v. Derwinski, 2 Vet. App. 141 (1992).

${ }^{49} \mathrm{http} / / / \mathrm{www} . v a . g o v / h e a l$ theligibility/Library/pubs/HealthCareOverview/

${ }^{50}$ Service connected ratings are established by VA Regional offices and reflect an official ruling by the VA as to the severity of injury or disease. As such, a person rated $50 \%$ or $70 \%$ has a disability that impacts them more severely than someone rated at $20 \%$. 
veteran for at least two years after he serves in a combat zone may receive high priority, free care with no co-payments. ${ }^{51}$ Moreover, compensation can be paid to veterans if their injury is also serviceconnected. $^{52}$ As interpreted by the Board of Veteran Appeals, the primary administrative body that reviews benefit claims, service connection requires facts demonstrating that a disease or injury, which results in current disability, was incurred or aggravated in active military service, or is proximately due to, or the result of, serviceconnected disease or injury. ${ }^{53}$ A veteran is entitled to service connection for a disability resulting from a disease or injury incurred or aggravated during active service. ${ }^{54}$ Service connection also is permissible for any "disease diagnosed after discharge, when all the evidence, including that pertinent to service, establishes the disease was incurred in service." $" 55$ Certain chronic diseases will be presumed to have been incurred or aggravated in service if manifested to a compensable degree within one year after service. ${ }^{56}$

Moreover, in order to establish a Total Disability based upon Individual Unemployability (TDIU), there must be impairment so severe that it is impossible for the average person to perform a substantially gainful occupation. ${ }^{57}$ In reaching such a determination, the central inquiry is whether the veteran's service-connected

5138 U.S.C. $\$ 1710(2000)$.

5238 U.S.C. $\S \S 1110,1131$.

5338 U.S.C.A. $\S \S 1110,5107$ (West 2002 \& Supp. 2005); 38 C.F.R. $\S \S 3.303,3.310$ (2005).

${ }^{54}$ See 38 U.S.C.A. $\S 1110$ (West 2002); 38 C.F.R. $\S 3.303(a)(2005)$.

${ }^{55} 38$ C.F.R. $\S 3.303(\mathrm{~d})(2005)$.

${ }^{56} 38$ U.S.C.A. $\S \S 1101,1112,1113$ (West 2002); 38 C.F.R. $\S \S 3.307,3.309$ (2005). This presumption is rebuttable by probative evidence to the contrary. If there is no evidence of a chronic condition during service, or during an applicable presumptive period, then a showing of continuity of symptomatology after service is required to support the claim. See 38 C.F.R. $\S 3.303$ (b) (2005). Evidence of a chronic condition must be medical, unless it relates to a condition to which lay observation is competent. See Savage v. Gober, 10 Vet. App. 488, 495-498 (1997). Compensation shall not be paid under this section if: (1) there is affirmative evidence that an undiagnosed illness was not incurred during active military, naval, or air service in the Southwest Asia theater of operations during the Persian Gulf War; (2) if there is affirmative evidence that an undiagnosed illness was caused by a supervening condition or event that occurred between the veteran's most recent departure from active duty in the Southwest Asia theater of operations during the Persian Gulf War and the onset of the illness; or (3) if there is affirmative evidence that the illness is the result of the veteran's own willful misconduct or the abuse of alcohol or drugs. 38 C.F.R. $\S 3.317$ (c) (2005).

${ }^{57} 38$ C.F.R. \& 3.340(a)(1) (2005). 
disabilities alone are of sufficient severity to produce unemployability. ${ }^{58}$ Total disability will be considered to exist when there is present any impairment of mind or body which is sufficient to render it impossible for the average person to follow a substantially gainful occupation; provided that permanent total disability shall be taken to exist when the impairment is reasonably certain to continue throughout the life of the disabled person. ${ }^{59}$

In order to prevail on the issue of service connection for any particular disability, there must be medical evidence of a current disability; or in certain circumstances, lay evidence of in-service occurrence or aggravation of a disease or injury; and medical evidence of a nexus between an in-service injury or disease and the current disability. ${ }^{60}$ Moreover, it is now well-settled that in order to be considered for service connection, a claimant must first have a current disability. ${ }^{61}$ Symptoms alone, without a finding of an underlying disorder, cannot be service-connected. ${ }^{62}$ This fact is critical primarily in connection with diseases that have been associated with the wars in Afghanistan and Iraq, including the Gulf War Syndrome. Because many veterans are clearly experiencing medical problems connected to the Gulf War Syndrome, continuance of medical care, evaluation, and treatment is necessary. Without recognition that the source of those problems is a result of their connection to the Gulf war, it creates greater public distrust of the Government and amplifies the role of stress in the thousands of veterans who are afflicted with the disease.

Moreover, whether a condition qualifies as a disability for VA purposes is a legal determination to be made by the Board of Veteran Appeals and not a medical professional. The Board may also weigh the credibility and probative value of medical opinions and may favor one medical opinion over another. ${ }^{63}$

In determining whether service connection is warranted for a disability, the VA is responsible for evaluating whether the evidence supports the claim or is in relative equipoise, with the veteran prevailing in either event, or whether a preponderance of the evidence

\footnotetext{
${ }^{58}$ Hatlestad v. Brown, 5 Vet. App. 524, 529 (1993).

5938 C.F.R. $\S 4.15$ (2005).

${ }^{60}$ See Hickson v. West, 12 Vet. App. 247, 253 (1999); see also Pond v. West, 12 Vet App. 341, 346 (1999).

${ }^{61}$ See Rabideau v. Derwinski, 2 Vet. App. 141, 143 (1992); Gilpin v. Brown, 155 F.3d 1353, 1355 (Fed. Cir. 1998).

${ }^{62}$ See Sanchez-Benitez v. Principi, 259 F.3d 1356, 1360 (Fed. Cir. 2001).

${ }^{63}$ See Evans v. West, 12 Vet. App. 22, 30 (1998) (citing Owens v. Brown, 7 Vet. App. 429, 433 (1995)).
} 
is against the claim, in which case the claim is denied. ${ }^{64}$ To do so, the Board of Veteran Appeals must assess the credibility and weight the evidence, including the medical evidence, to determine its probative value, accounting for evidence that it finds to be persuasive or unpersuasive, and providing reasons for rejecting any evidence favorable to the appellant. ${ }^{65}$

Because so much of what veterans may receive depends on the relatedness of the disability to their time in combat, most legal actions revolve around whether the disability is service-connected as well as the extent of the disability itself.

In order to receive monthly compensation, for example, the veteran must be at least $10 \%$ disabled as a result of military service. ${ }^{66}$ As the disability increases, so does the monthly compensation. In 2008 , single veterans can get monthly service-connected compensation awards for disabilities that cause partial incapacity in increments of $10 \%(\$ 117), 20 \%(\$ 230), 30 \%$ (\$358), 40\% (\$512), 50\% (\$728), $60 \%$ $(\$ 921), 70 \%(\$ 1,161), 80 \%(\$ 1,349)$ or $90 \%(\$ 1,517)$-and, of course, at a full $100 \%(\$ 2,527) .{ }^{67}$ The distinction between monthly rates depending on compensation is significant enough in order to encourage veterans to appeal decisions. ${ }^{68}$ For example, a veteran evaluated at $70 \%$ disabled would receive approximately $\$ 5,000$ more on a yearly basis than a veteran who was classified as $50 \%$ disabled. $^{69}$

However, the line between who is $50 \%$ and $70 \%$ disabled is generally not that clear. As such, the classification of a patient degree of psychological disorder is considered in light of the actual symptoms of the disorder, which also provide the primary basis for the rating assigned. $^{70}$ Disability evaluations are determined by comparing a veteran's present symptomatology with criteria set forth in the VA's Schedule for Rating Disabilities, which is based on average impairment in earning capacity. ${ }^{71}$

In evaluating PTSD, a veteran whose injuries are characterized, primarily, by anxiety, guilt, depressed mood, sleep disturbances,

\footnotetext{
${ }^{64}$ Gilbert v. Derwinski, 1 Vet. App. 49, 57 (1990).

${ }^{65}$ See Masors v. Derwinski, 2 Vet. App. 181, 185 (1992).

${ }^{66} \mathrm{http}: / / \mathrm{www} . v b a . v a . g o v /$ benefit_facts/General/English/VAP21-00-12\%20January\% 202006.pdf.

${ }^{67} \mathrm{http} / / / \mathrm{www} . v b a . v a . g o v / \mathrm{bln} / 21 /$ rates/comp01.htm.

${ }^{68}$ See generally Richard v. Brown, 9 Vet. App. 266, 267 (1996); Carpenter v. Brown, 8 Vet. App. 240 (1995).

${ }^{69} \mathrm{Id}$.

${ }^{70}$ See 38 C.F.R. $\$ 4.126($ a).

${ }^{71} 38$ U.S.C.A. $\S 1155 ; 38$ C.F.R. Part 4.
} 
nightmares, intrusive recollections, and occasional problems with concentration. $^{72}$ These symptoms are reflective of occupational and social impairment with no more than reduced reliability and productivity, the level of impairment contemplated in the currently assigned $50 \%$ disability rating. ${ }^{73}$ A $70 \%$ evaluation is warranted for occupational and social impairment with deficiencies in most areas, such as work, school, family relationships, judgment, thinking or mood, due to such symptoms as: suicidal ideation; obsessional rituals which interfere with routine activities; speech intermittently illogical, obscure, or irrelevant; near- continuous panic or depression affecting ability to function independently, appropriately and effectively; impaired impulse control (such as unprovoked irritability with periods of violence); spatial disorientation; neglect of personal appearance and hygiene; difficulty in adapting to stressful circumstances (including work or a work-like setting); and inability to establish and maintain effective relationships. ${ }^{74}$ A $100 \%$ evaluation is warranted for total occupational and social impairment, due to such symptoms as: gross impairment in thought processes or communication; persistent delusions; grossly inappropriate behavior; persistent danger of hurting self or others; intermittent ability to perform activities of daily living (including maintenance of minimal personal hygiene); disorientation to time or place; and memory loss for names of closes relatives, own occupation, or own name. ${ }^{75}$

As a result of the vague distinctions between the levels of PTSD, veterans are encouraged to exaggerate symptoms in order to benefit for military coverage. Moreover, the ambiguity between levels of PTSD has seen an increased number of appeals to VA decisions as well as caused uncertainty by veterans as to the nature of benefits they are entitled.

Similarly, the stark contrast between care given to those who suffer service connected disabilities and those who do not is likely to do more to encourage administrative actions and confusion then to resolve genuine issues of medical need. For disabilities which are not service connected, veterans are only eligible for the VA pension, a

\footnotetext{
7238 C.F.R. § 4.130, Diagnostic Code 9411

${ }^{73}$ Board of Veterans Appeal, Citation Nr. 0603730, available at http://www.va.gov/ vetapp06/files $2 / 0603730 . t x t$.

${ }^{74} I d$.

${ }^{75} \mathrm{Id}$.
} 
benefit paid to wartime veterans with limited income and who are permanently and totally disabled, or 65 or older. ${ }^{76}$

Given how important it is for disabilities to be designated or denied as service-connected, it is equally significant that as a matter of policy a number of diseases have been presumed to be serviceconnected or denied as a matter of law. One contentious area involves determinations about injuries arising from the use of hazardous United States weaponry, in particular whether the Gulf War Syndrome is a service connected disease.

The Gulf War syndrome is an illness reported by veterans of both Gulf Wars as well as the war in Afghanistan. The disease is generally characterized ${ }^{77}$ by fibromyalgia, ${ }^{78}$ chronic fatigue syndrome, eczema, $^{79}$ and dyspepsia. ${ }^{80}$ As of late, the Research Advisory Committee on Gulf War Veterans has concluded that the disease is potentially a result of a number of difference causes including: the use of depleted uranium, side effects of anthrax vaccine, infectious diseases from parasites, the use of chemical weapons, or a combination of them all. ${ }^{81}$ In addition, a number of substances were found to be associated with increased symptoms of the disease, including military issued pesticides and insect repellants and pyridostigmine bromide, a protection against nerve agents. As such, most of the causes relating to the illness arise from medication or weapons utilized by the United States military. ${ }^{82}$

${ }^{76}$ In 2008 , the pension level for a single veteran without dependents is $\$ 931.75+$ monthly and additional amounts are paid for invalids and those with dependents.

77 See generally ANNALS OF InTERnal MEdicine. Gulf WaR VETERANS' Health: Medical Evaluation of a U.S. Cohort. June 7, 2005.

${ }^{78}$ Fibromyalgia is a disorder characterized by the presence of chronic widespread pain, debilitating fatigue, abnormal sleep patterns, bowel disturbances, anxiety and depression. See Frederick Wolfe et al. (February 1990). The American College of Rheumatology 1990 Criteria for the Classification of Fibromyalgia. Report of the Multicenter Criteria Committee, 33 ARTHRITIS AND RHEUMATISM 160 (1990).

${ }^{79}$ Eczema is identified by the inflammation of the upper layers of the skin. See generally S.J.O Johansson et al., A revised nomenclature for allergy. An EAACI position statement from the EAACI nomenclature task force, 56 ALLERGY 813 (2001); C. Bridgett, Psychodermatology and Atopic Skin Disease in London 1989-1999 Helping Patients to Help Themselves, 4 DeRmatology AND Psychosomatics 183 (2000).

${ }^{80}$ Dyspepsia is evidenced by chronic or recurrent pain or discomfort centered in the upper abdomen. Nicholas Talley, et al., Guidelines for the Management of Dyspepsia, 100 AM. J. GaStroenterology 2324 (2005).

${ }^{81}$ Research AdVISORY COMmitTeE ON GULF WAR Veterans' IllnesSES DeC. 12 13, 2005 COMM. MEETING MinUTES.

${ }^{82}$ Id. at $148,154,156$. 
Despite this fact, or as a result of it, service connection for "Gulf War Syndrome" is denied as a matter of law. ${ }^{83}$ On November 2, 1994, Congress enacted the "Persian Gulf War Veterans' Act." 84 The statute added section 1117 to Title 38 of United States Code, authorizing VA to compensate any Persian Gulf veteran suffering from a chronic disability resulting from an undiagnosed illness or combination of undiagnosed illnesses, which became manifest either during active duty in the Southwest Asia theater of operations during the Persian Gulf War, or to a degree of $10 \%$ or more within a presumptive period following service in the Southwest Asian theater of operations during the Persian Gulf War. VA issued and later revised a regulation that also addresses claims for service connection for disabilities arising from undiagnosed illness. ${ }^{85}$

Under the law and the regulation, however, the focus for service connection purposes is not on what may have caused the disabilities of Gulf War veterans (i.e., smoke from oil well fires, bites from sand fleas, exposure to nerve gas, reactions to anthrax vaccinations, etc.), but rather on the specific disabilities themselves (e.g., joint pain, headaches, respiratory symptoms, etc.). This is because once service connected, the specific, chronic disability is evaluated under its analogous diagnostic code. ${ }^{86}$ Moreover, to date, VA has not specifically recognized "Persian Gulf Syndrome" or "Gulf War Syndrome" as a compensable disability itself. ${ }^{87}$

Nor has the VA recognized that exposure to chemicals used in the United States military provide a presumption for service-connected injury. In fact, the Secretary of Veterans Affairs has determined that there is no basis for establishing a presumption of service connection for any illness suffered by Gulf War veterans based on exposure to depleted uranium, sarin, pyridostigmine bromide, and certain vaccines. $^{88}$

Additionally, the VA does not recognize alcoholism ${ }^{89}$ or drug addiction $^{90}$ as compensable disabilities themselves (nor does it for

${ }^{83} 38$ U.S.C. $\S 1117$ (Supp. West 2002); 38 C.F.R. $\S 3.317$ (2005); 60 Fed. Reg. 6660 , 6661 (1995); Sabonis v. Brown, 6 Vet. App. 426, 430 (1994).

${ }^{84}$ Title I of the "Veterans' Benefits Improvements Act of 1994," Public Law 103-446. 8538 C.F.R. $\S 3.317$.

${ }^{86}$ See M21 - 1, Part VI, Paragraph 7.22 (2005).

${ }^{87}$ See 60 Fed. Reg. 6660, 6661 (1995).

${ }^{88} 66$ Fed. Reg. 35,702-10 (2001); 66 Fed. Reg. 58,784-85 (2001).

${ }^{89}$ Section 8052 of the Omnibus Budget Reconciliation Act of 1990, Pub. L. No. 101$508, \S 8052$, 104 Stat. 1388, 1388-91, prohibits payment of compensation for a disability that is a result of a veteran's own alcohol or drug abuse, effective for claims 
pensions). ${ }^{91}$ However, underlying psychological disabilities that might give rise to alcoholism or drug addiction as symptoms are compensable, and, in those cases, alcoholism or drug addiction histories can even serve as symptom evidence to buttress such claims. ${ }^{92}$ Moreover, injuries or illnesses resulting from illegal activities can never, under the law, be compensable. In practice, however, only those illegal activities which are obvious, or admitted to by a veteran while still on active duty or during questioning by VA staff are actually considered illegal.

Political forces play a major part in forming the rules associated with classifying or rejecting certain diseases as service connected. ${ }^{93}$ Rules in force since early 2003 provide that in-country Vietnam veterans who now have diabetes are presumed to be service connected if the disability is rated at least $10 \%,{ }^{94}$ with higher ratings possible for serious diabetic complications. ${ }^{95}$ Moreover, current tracheal, laryngeal, bronchial and lung cancers and chronic lymphocytic leukemia of incountry Vietnam War veterans can be presumed to be service connected due to exposure to Agent Orange. ${ }^{96}$ Lastly, Veterans of the

filed after October 31, 1990. Moreover, Section 8052 was also amended 38 U.S.C.A. $\S 105$ (a) to provide that, with respect to claims filed after October 31, 1990, an injury or disease incurred during active service will not be deemed to have been incurred in line of duty if the injury or disease was a result of the person's own willful misconduct, including abuse of alcohol or drugs. See 38 U.S.C.A. $\$ 105 ; 38$ C.F.R. $\S \S 3.1(\mathrm{~m}), 3.301(\mathrm{~d})$.

${ }^{90}$ See 38 U.S.C.A. $\S 105 ; 38$ C.F.R. $\S \S 3.1(\mathrm{~m}), 3.301(\mathrm{~d})$. VA's General Counsel has confirmed that direct service connection for a disability that is a result of a claimant's own abuse of alcohol or drugs is precluded for purposes of all VA benefits for claims filed after October 31, 1990. See VA O.G.C. Prec. Op. No. 7-99 (June 9, 1999); VA O.G.C. Prec. Op. No. 2-98 (Feb. 10, 1998).

91 Compensation shall not be paid under this section if: (1) there is affirmative evidence that an undiagnosed illness was not incurred during active military, naval, or air service in the Southwest Asia theater of operations during the Persian Gulf War; (2) if there is affirmative evidence that an undiagnosed illness was caused by a supervening condition or event that occurred between the veteran's most recent departure from active duty in the Southwest Asia theater of operations during the Persian Gulf War and the onset of the illness; or (3) if there is affirmative evidence that the illness is the result of the veteran's own willful misconduct or the abuse of alcohol or drugs. 38 C.F.R. $\S 3.317$ (c).

9238 C.F.R. $\$ 3.301$ (d) (2007)

${ }^{93}$ See Department of Veteran Affairs, "Presumptive" Disability Benefits for Certain Groups of Veterans available at http://www.vba.va.gov/benefit_facts/ServiceCon nected_Disabilities/English/Presumpeg_0307.doc (last visited Apr. 25, 2008)

${ }^{94} 20 \%$ if also on regular medication for diabetes.

${ }^{95}$ See 38 U.S.C.A. $\S \S 1101,1112,1113,1137$; 38 C.F.R. $\S \S 3.307,3.309$.

${ }^{96} \mathrm{http} / / / \mathrm{www} . v a . g o v /$ vetapp97/files1/9704924.txt. 
First Gulf War who now have amyotrophic lateral sclerosis, also known as Lou Gehrig's Disease, are automatically presumed to have a service connected disability. ${ }^{97}$ In 2004 , the VA also began automatically presuming multiple sclerosis in Vietnam and post-Vietnam war zone veterans as being service connected. $^{98}$

\section{CONCLUSION}

Insufficient medical coverage and pension plans for returning veterans are a significant problem that is likely to increase in upcoming years as more soldiers are engaged in asymmetrical wars, where the conditions and nature of battle are more chaotic and abnormal. The very nomenclature utilized by the Bush Administration to define the current conflicts in Iraq and Afghanistan, the "War on Terror," certifies that the nature of the threat soldiers are confronting are both amorphous and spread throughout the world. As such, it is likely that as the US government confronts the "War on Terror," soldiers will be placed in more remote areas for extended period of times and in light of threats from unconventional sources. Altogether, these conditions demonstrate the need and importance of psychological care for present and future veterans.

In addition, patterns of warfare from the Vietnam War to the present day show that as military weapons and training become more modernized, the use biological or chemical agents has increased the possibility that soldiers are subject to new and emerging disorders that are unforeseen by traditional care. Despite the importance of confronting such medical disorders early, the current politicization of medical care often results in major medical diseases being rejected from coverage. Policy limitations that categorically reject recognition of illnesses arising from the use of US and foreign weaponry is more likely to cause enhance stress conditions suffered by veterans upon their return.

While Congress certainly has plenary power to determine the limitations of VA care, including defining what diseases do and do not constitute a "service connected" disability, it is to Congress's advantage to accept diseases that may be a product of US weapons or immunizations in order to assist veterans reconcile their issues and gradually be reincorporated into the general public. Without such

${ }^{97}$ See 38 C.F.R. $\$ 3.309$ (e).

${ }^{98}$ See 38 U.S.C.A. $\S \S 1101,1112,1113,1137$ (1991); 38 C.F.R. $\S \S 3.307,3.309$ (1998). 
recognition, it is highly likely that Congress will be faced with continuous public attacks. To engage in such political defense decreases the American public's trust Congressional and Executive capacities for providing veteran care and in managing military conflicts altogether. Consequently, without remedying the need for medical aid, Congress and the President face significant hurdles in providing for the common defense of the US. 